\title{
Evaluation of the Future of the Patients Operating on a Switching Mandibuletomy in Madagascar
}

\author{
Simon Carnot Ndrianarivony*, Fenosoa Vonimbola D'Assise Rakotoarimanana, \\ Andrandraina Iavosoa Randrianantoandro, Rantonirina Henri Andriamanantena, \\ John Bam Razafindrabe
}

Department of Maxillo-Facial Surgery, University Hospital of Befelatanana, Antananarivo, Madagascar

Email: ^nsimoncarnot@gmail.com

How to cite this paper: Ndrianarivony, S.C., Rakotoarimanana, F.V.D., Randrianantoandro, A.I., Andriamanantena, R.H. and Razafindrabe, J.B. (2021) Evaluation of the Future of the Patients Operating on a Switching Mandibuletomy in Madagascar. Surgical Science, 12, 37-45.

https://doi.org/10.4236/ss.2021.123006

Received: January 15, 2021

Accepted: March 2, 2021

Published: March 5, 2021

Copyright $\odot 2021$ by author(s) and Scientific Research Publishing Inc. This work is licensed under the Creative Commons Attribution International License (CC BY 4.0)

http://creativecommons.org/licenses/by/4.0/

\begin{abstract}
Introduction: Interruptive mandibulectomy is often unavoidable despite the functional postoperative handicaps that it generates. Plate reconstruction is the only possible reconstruction in CHUDR Antananarivo. The objective of this study is to evaluate the oral-facial functional status of patients who have undergone interruptive mandibulectomy. Methods: It is a descriptive and transversal retrospective study of 18 months from January 17, 2017 to July 17, 2018. We retained 30 patients who had undergone an interruptive mandibulectomy in the ward during the study period. We studied the state of mastication, phonation, pain, swallowing, labial continence, psychological state, deformity and satisfaction. Patients were classified into 3 groups according to type of intervention A, B and C. Results: Thirty patients were included. The type $\mathrm{C}$ intervention was the most frequent, followed by types $\mathrm{B}$ and $\mathrm{A}$. The postoperative follow-up period ranged from 1 to 23 months. Chewing disorder has been encountered in more than half of cases. The phonation disorder was found in groups B and C. We found 13 cases of deformity. Patients became well integrated into society after surgery. Conclusion: Mandibulectomy creates aesthetic and functional prejudices for patients. Despite these disorders, patients adapt well to their daily lives.
\end{abstract}

\section{Keywords}

Chewing, Deglutition, Esthetics, Mandible, Speech

\section{Introduction}

Mandibulectomy is a maxillofacial surgical procedure that involves removing all or part of the mandible [1]. This resection can be marginal segmental and only 
concerns a small part of the bone, teeth and corresponding soft tissues, or interruptive that the bone is completely cut off. It is then a larger part of the mandible that is concerned switching. The operation will usually be followed by bone graft reconstruction and/or implant placement [1] [2] [3]. Interrupting mandibulecto$\mathrm{my}$, in the face of a tumor pathology, is often unavoidable despite the postoperative functional handicap, in particular mastication, aesthetic and psychological it causes [4] [5] [6] [7]. Beyond the indication for a bone graft, the only current reconstruction possible in the maxillofacial surgery department of the Joseph Dieudonné Rakotovao University Hospital Center Madagascar (CHUJDR) is plate reconstruction otherwise we are satisfied with an excision of the tumor without reconstruction. The objective of our study is to assess the oral and facial functional status of patients who have undergone interrupter mandibulectomy.

\section{Materials and Method}

- Description of the study

This is a descriptive, cross-sectional retrospective study. This is a study carried out in the Maxillofacial Surgery Department of CHUJDR Befelatanana Antananarivo Madagascar. The study period lasts 18 months from January 17, 2017 to July 17, 2018.

- Study population

The patients were selected from their medical files, sorted within the Maxillofacial Surgery department of the CHUJDR Befelatanana Antananarivo. We included all patients who had undergone an interruptive mandibulectomy under general anesthesia in the ward during the study period. We evaluated the patients either during control or after a telephone conversation Incomplete files were excluded.

- The parameters studied were

- The type of intervention: we have classified the intervention into 3 types (Figure 1): types A, B, C (removed from the classification of David and SFC) [4]. A: resection in front of the mandibular angle and without going beyond the contralateral canine or intervention involving only part of the horizontal branch. He will have preserved part of the supra hyoid muscles and the elevator muscles of the mandible. B: resection behind the angle with preservation of the condyle and without going beyond the contralateral canine, it will have a disinsertion of the elevator muscles of the mandible except the lateral pterygoid but conservation of the condyle with a possibility of reconstruction. C: Hemimandibulectomy and/or resection involving more than half of the mandible. We classified the patients into 3 groups: the patients who received a type A intervention are called group A, group B the type B intervention and group $\mathrm{C}$ for the type $\mathrm{C}$ intervention.

- Chewing: we gave a score from 0 to 3 to assess the degree of chewing disorder. 0: without chewing disorder or normal chewing; 1: mild disorder where the patient can eat solid food but not too hard; 2: moderate cloudiness, food is soft; 3 : severe disorder where the patient can only swallow liquid. 


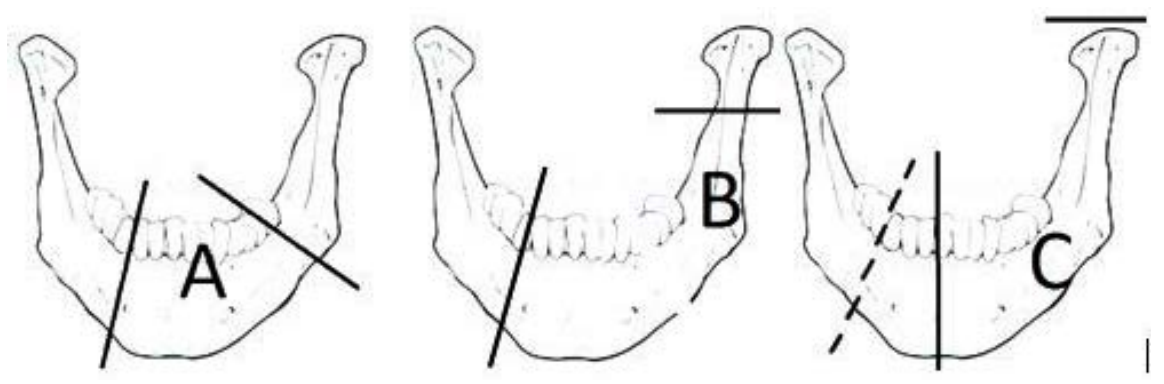

Figure 1. Representation of 3 types mandibulectomy in our study.

- Pain on chewing we used the Washington University questionnaire to assess pain. Level I: no pain; Level II: minimal pain that does not require analgesia; Level III: moderate pain requiring an analgesic; Level IV: severe pain controlled only by medication; Level V: very severe pain, not controlled by drugs.

- Swallowing; speech, lip continence, facial deformity which we rated as 0 and 1; 0 : absence of cloudiness; 1 : presence of cloudiness. The lower limit of the postoperative follow-up time is more than 1 month after the operation.

- The social relationship: we ranked it in two: a bad and a good social adaptation.

- Psychological disorder: we gave a scale of 0 to 1, 0: No psychological harm; 1: Psychological impairment such as anxiety, depression.

- Data analysis: the study was realized by the software Epi info ${ }^{\circledR}$ and Excel xp $2018^{\circledR}$.

\section{Results}

We retained 33 files. The most frequently performed procedures were type $\mathrm{C}$ and type B (Table 1). On average, the patients have low socio-economic levels. The postoperative follow-up was between 1 to 23 months and we followed up the patients every 6 months. In $43.3 \%$ of cases, patients were evaluated within 6 months of surgery. In half of the cases, the patients in group A presented a slight disturbance during chewing. For intervention type B, we found 4 cases (36.3\%) of mild disorder and 5 cases $(45.4 \%)$ of moderate chewing disorder. For group C patients; $61.5 \%$ of the patients $(\mathrm{Nb}=8)$ presented a moderate disorder and $23.0 \%$ ( 3 cases) had a mild disorder (Table 2). The 3 groups of patients presented no swallowing disorder. The speech disorder was found in 2 cases (33.3\%) for type A; 6 cases (54.5\%) that of type B and 4 cases (30.7\%) for type C. The type $B$ intervention gave more speech disorder than the other types. We did not object labial continence disorder for our patients. For types A and C we did not object to pain during chewing while for type B two patients (18.1\%) had minimal pain (Table 3). We found that in the majority of cases our patients presented moderate chewing disturbances before 6 months, then chewing improved within 6 months to return to almost normal for type A after 18 months of the intervention. The 2 cases of the phonation disorder appeared after 12 months of 
Table 1. Types of intervention distribution.

\begin{tabular}{ccc}
\hline Type & $\begin{array}{c}\text { Effective } \\
\mathrm{n}=30\end{array}$ & $\begin{array}{c}\text { Frequency } \\
100 \%\end{array}$ \\
\hline A & 6 & $20.0 \%$ \\
B & 11 & $36.6 \%$ \\
C & 13 & $43.3 \%$ \\
\hline
\end{tabular}

Table 2. Repartition of chewing disorder in our study.

\begin{tabular}{ccccccc}
\hline & \multicolumn{2}{c}{ Group A } & \multicolumn{2}{c}{ Group B } & \multicolumn{2}{c}{ Group C } \\
\cline { 2 - 6 } & $\begin{array}{c}\text { Effective } \\
\mathrm{n}=6\end{array}$ & $\begin{array}{c}\text { Frequency } \\
100 \%\end{array}$ & $\begin{array}{c}\text { Effective } \\
\mathrm{n}=11\end{array}$ & $\begin{array}{c}\text { Frequency } \\
100 \%\end{array}$ & $\begin{array}{c}\text { Effective } \\
\mathrm{n}=13\end{array}$ & $\begin{array}{c}\text { Frequency } \\
100 \%\end{array}$ \\
\hline Note 0 & 2 & $33.3 \%$ & 2 & $18.1 \%$ & 1 & $7.6 \%$ \\
Note 1 & 3 & $50.0 \%$ & 4 & $36.3 \%$ & 3 & $23.0 \%$ \\
Note 2 & 1 & $16.6 \%$ & 5 & $45.4 \%$ & 8 & $61.5 \%$ \\
Note 3 & 0 & $0.0 \%$ & 0 & $0.0 \%$ & 1 & $7.6 \%$ \\
\hline
\end{tabular}

Table 3. Representation of chewing pain by type of intervention.

\begin{tabular}{|c|c|c|c|c|c|c|c|}
\hline \multirow[b]{2}{*}{ Pain } & \multirow[t]{2}{*}{ Type } & \multicolumn{2}{|c|}{ Group A } & \multicolumn{2}{|c|}{ Group B } & \multicolumn{2}{|c|}{ Group C } \\
\hline & & $\begin{array}{c}\text { Effective } \\
n=6\end{array}$ & $\begin{array}{c}\text { Percentage } \\
100 \%\end{array}$ & $\begin{array}{c}\text { Effective } \\
\mathrm{n}=11\end{array}$ & $\begin{array}{c}\text { Percentage } \\
100 \%\end{array}$ & $\begin{array}{c}\text { Effective } \\
\mathrm{n}=13\end{array}$ & $\begin{array}{c}\text { Percentage } \\
100 \%\end{array}$ \\
\hline I & & 6 & $100.0 \%$ & 9 & $81.8 \%$ & 13 & $100.0 \%$ \\
\hline II & & 0 & $0.0 \%$ & 2 & $18.1 \%$ & 0 & 0 \\
\hline III & & 0 & $0.0 \%$ & 0 & $0.0 \%$ & 0 & 0 \\
\hline IV & & 0 & $0.0 \%$ & 0 & $0.0 \%$ & 0 & 0 \\
\hline V & & 0 & 0 & 0 & $0.0 \%$ & 0 & 0 \\
\hline
\end{tabular}

the operation for type A. For type B, 4 out of 6 cases, or $66.6 \%$, appeared after this same period. On the other hand for type $C$, in half of the cases the phonation disorder appeared before 12 months postoperatively. Not all of our patients had a problem re-integrating into society. We found that the surgery did not cause any psychological disturbance for our patients. One case (7.1\%) of facial deformity was found in group A. five cases (35.7\%) presented it for type B and 8 cases $(57.1 \%)$ that of group C. Type B and C interventions gave more deformation of the face.

\section{Discussion}

The interrupting mandibulectomy anterior to the mandibular angle resulted in mild chewing disturbance. In addition, posterior angle resection with preservation of the condyle presented moderate disorder in almost half of the cases. The disorder mostly occurred in patients with mandibular reconstruction in $30.0 \%$ of cases [4]. The chewing disorder is explained by the disinsertion of the mastica- 
tory muscles, namely the suprahyoid muscles, the masseter and the medial pterygoid [4] [8]. Maed et al. carried out a study in 2018 in Japan concerning the quality of life of mandibulectomized patients [5]. They assessed chewing by asking the patient to chew gum and assessed the color change (from gray to red). They concluded that he did not have a significant difference in the chewing of his patients compared to a person without a mandibulectomy. The chewing disorder is major for patients who do not have reconstruction, it is better tolerated in patients who have a bone graft and those who wear removable dentures, but the disorder is much more severe when patients have removed their prosthesis compared to those who did not wear them [9]. In contrast to our study, patients who received plaque reconstruction had a lot of trouble compared to those who did not. This can be explained by the non-adaptation of patients to the reconstruction plate used [10] [11]. The literature speaks that the lateral interrupter mandibulectomy gives more chewing disorder while the anterior mandibulectomy gives a phonation disorder [4] [6] [12]. Indeed the chewing disorder occurs in patients who had undergone a lateral mandibulectomy, the larger the size of the loss of substance, the greater the disorder. The disorder is improved by compensating for the loss of substance [13].

Patients with large loss of substance frequently present with a joint disorder. Seikaly et al. [14] observed that patients who underwent mandibulectomy followed by reconstruction with fibula grafting did not exhibit any speech impairment. This difference compared to our study can be explained by the compensation of the loss of substance by fibula graft by this team when we had only used a reconstruction plate or even without reconstruction. The literature speaks that an interrupting mandibulectomy could result in a joint disorder caused by the reduced mobility of the tongue, the occurrence of glossoptosis as well as the air leakage left by the loss of mandibular substance [4] [15]. Thus, speech therapy is essential after surgery to restore the articulation of speech [16]. In general, there will be no more pain when chewing after the procedure if there is no mechanical complication [17] [18].

Our patients did not have any swallowing disorder. Bone and tooth loss leads to swallowing disorder due to disturbance of the chewing time of swallowing [19]. In the literature, patients who have had a segmental mandibulectomy have presented with swallowing disorder due to the disinsertion of the genioglossal and geniohyoid muscles which would have resulted in the tongue falling back [4] [20] [21]. This discrepancy could be due to the insufficiency of the study concerning the swallowing of mandibulectomized patients. Some authors have concluded that swallowing disorders occur after pelviglossomandibulectomy which will lead to a disturbance in the mobility of the tongue and the formation of the bolus [22].

All the patients in our study all had good labial continence. The labial musculature and its innervation are not compromised by the mandibulectomy. A study done by Okoturo et al. in 2011 found that lip continence is for mandibulectomized patients undergoing reconstruction [18]. Another study by Goiato et al. 
[22] found that the placement of mandibular prosthesis after segmental mandibulectomy preserves good labial continence. A case of labial incontinence was reported in 2009 [23] in a 60-year-old woman who presented with a malignant tumor of the oral cavity affecting the mandible and part of the base of the tongue. This woman had undergone a segmental mandibulectomy and glossectomy. They monitored the state of the woman's labial continence. She did not have an immediate postoperative continence disorder for up to 9 months. At 25 months after the operation, the patient presented with labial incontinence by thickening of the lower inner lip by fibrosis after infection. Another case of lip incontinence was reported by Chakravarthy in India in 2009 [24] in a 25-year-old young man who had undergone a marginal mandibulectomy between 47 and 37 . For this time the lip incontinence was due to a lesion of the branch of the facial nerve. They compensated for this disorder by placing a lower lip prosthesis. The literature speaks that anterior mandibulectomized patients have a labial continence disorder due to mandibular arch loss, labial sensitivity disorder by section of the mandibular nerve and facial paralysis by section of the chin branch of the facial [4]. This contradiction to the literature may be due to insufficient study on this topic and could be that patients can retain their saliva even in the absence of the mandibular arch. But we can say that in the absence of a factor favoring the formation of fibrosis and nerve damage, the interrupter mandibulectomy does not really lead to salivary incontinence [2].

According to our results, the chewing disorder occurred before 6 months of the operation for all 3 groups. The phonation disorder appeared after 12 months for groups A and B, before 12 months that of type C. Namaki S et al. in 2004 [25] in Tokyo speaks that mandibulectomized patients present a progressive decrease in the masticatory coefficient until the 6th month and an increasing trend after 12 months. The chewing disorder occurs before 12 months after surgery due to bone loss as well as the disinsertion of certain masticatory muscles which will lead to a gradual decrease in masticatory capacity. The phonation disorder appears after 12 months of the operation in most cases because after this time the formation of fibrosis sets in as well as the onset of glossoptosis [21] [25].

Lateral interrupter mandibulectomy (Type B and C) frequently results in deformity of the face [17]. The use of a temporal muscle flap to compensate for the loss of substance and the wearing of removable dentures improves facial deformity [18]. According to the study by Yang et al. that we have seen previously, the deformity was only seen in $17.0 \%$ of cases because all his patients all benefited from a reconstruction by free fibula flap [15]. This difference from our study can be explained by the fact that our patients only benefit from reconstruction plates. In the literature [4] [6], lateral mandibulectomy would have resulted in facial deformity due to muscle retraction and bone loss. This deformity is improved by compensating for the loss of bone substance [26].

According to our results, none of our patients presented with any psychological disorder after surgery. The deformity and masticatory functional failure would be well accepted because of the healing of the pathology probably. A 2014 
study by Yang et al. on the quality of life of mandibulectomized patients followed by fibula graft reconstruction [13] found psychological repercussions. This difference from our study may be due to the difference in the effectiveness of psychological support given to patients. Because all of our patients all had psychological support before and after the operation. In fact, mandibulectomized patients can present with psychological instability after the operation, this is understandable but it depends on the quality, the effectiveness of the psychological support given to the patients, and the psychological state of the patient [13] [16].

In our study, all patients have a good social adjustment after surgery. According to the study carried out by Yang et al. [15], social disability took the minimum OHIP score, i.e. 35.2 on average and a median of 34.0 , i.e. it $\mathrm{n}$ did not affect the quality of life of patients. This ties in with our study. Luo et al. objected that social disability had a minimum mean score of 35.3 which means that his patients had no social problem [17]. Indeed, despite the intervention performed on patients and the morphological and functional consequences engendered by the surgery, they are integrating well into society. They accept the results well.

\section{Conclusion}

For many reasons, mandibulectomy is essential. It still generates anatomical defect and functional disorders. We evaluated after a follow-up of 1 to 23 months the functional status of patients operated for interrupting mandibulectomy. The limit of our study is the small size of sample. In fact, patients present with a chewing disorder in most cases regardless of the type of intervention, the larger the size of the bone loss, the greater the disorder. Speech joint disorder occurs in almost a third of our patients' cases. There is no impairment of swallowing and salivary continence. The facial deformity is present in half of cases; it is major during a lateral mandibulectomy. Our patients do not have a problem with social integration and the intervention did not cause them psychological instability. Despite the existence of these disorders, patients still adjust to daily life.

\section{Conflicts of Interest}

The authors declare no conflicts of interest regarding the publication of this paper.

\section{References}

[1] Qiu, Y., et al. (2017) Mandibulectomy in Oral Squamous Cell Carcinoma. Journal of Oral and Maxillofacial Surgery, 1, 1-6.

[2] Kadota, C., Sumita, Y.I., Wang, Y., Otomaru, T., Mukohyama, H., Fueki, K., et al. (2008) Comparison of Food Mixing Ability among Mandibulectomy Patients. Journal of Oral Rehabilitation, 35, 408-414. https://doi.org/10.1111/j.1365-2842.2007.01814.x

[3] Patil, P.G. (2010) Conventional Complete Denture for a Left Segmental Mandibulectomy Patient: A Clinical Report. Journal of Prosthodontic Research, 54, 192-197. 
https://doi.org/10.1016/j.jpor.2009.12.003

[4] Zakaria-Chuiton, R. (2010) Chirurgie interruptrice latérale mandibulaire: Réhabilitation fonctionnelle odontologique. These, Chirurgie dentaire: Nantes, $99 \mathrm{p}$.

[5] Maed, M., Hirose, M., Wada, K., Kishimoto, M., Akashi, M., Kimoto, A., et al. (2018) Elucidating the Masticatory Function and Oral Quality of Life According to the Range of Mandibulectomy. Journal of Oral and Maxillofacial Surgery, Medicine, and Pathology, 30, 220-224. https://doi.org/10.1016/j.ajoms.2018.01.004

[6] Vigaros, E. and Pradiness, M. (2007) Fusaro. Réhabilitation prothétique des pertes de substance mandibulaire d'origine carcinologique. Encyl Méd Chir; 22-066-B-51.

[7] Patback, K.A. (2009) Marginal Mandibulectomy: 11 Years of Institutional Experience. Journal of Oral and Maxillofacial Surgery, 67, 962-967.

https://doi.org/10.1016/j.joms.2008.08.019

[8] Marunick, M., Mathes, B.E., Klein, B.B. and Seyedsadr, M. (1992) Occlusal Force after Partial Mandibular Resection. Journal of Prosthetic Dentistry, 67, 835-838. https://doi.org/10.1016/0022-3913(92)90596-3

[9] Mochizuki, Y., Omura, K., Harada, H., Marukawa, E., Shimamoto, H. and Tomioka, H. (2014) Functional Outcomes with Dental Prosthesis Following Simultaneous Mandibulectomy and Mandibular Bone Reconstruction. Journal of Prosthodontic Research, 58, 259-266.

[10] Van der Bilt, A., Olthoff, L.W., Bosman, F. and Oosterhaven, S.P. (1994) Chewing Performance before and after Rehabilitation of Post-Canine Teeth in Man. Journal of Dental Research, 73, 1677-1683. https://doi.org/10.1177/00220345940730110201

[11] Otomaru, T., Sumita, Y.I., Chang, Q., Fueki, K., Igarashi, Y. and Taniguchi, H. (2009) Investigation of Predictors Affecting Food Mixing Ability in Mandibulectomy and/or Glossectomy Patients. Journal of Prosthodontic Research, 53, 111-115. https://doi.org/10.1016/j.jpor.2009.02.003

[12] Schünke, M., Schulte, E., Schumacher, U. and Vitte, E. (2016) Atlas d'anatomie Promethée: Tome 2-Tête, cou et neuroanatomie. De Boeck Université, Louvainla-Neuve, $600 \mathrm{p}$.

[13] Curtis, D.A., Plesh, O., Miller, A.J., Curtis, T.A., Sharma, A., Schweitzer, R., et al. (1997) A Comparison of Masticatory Function in Patients with or without Reconstruction of the Mandible. Head Neck, 19, 287-296. https://doi.org/10.1002/(SICI)1097-0347(199707)19:4<287::AID-HED7>3.0.CO;2-X

[14] Haddaji, A.M. (2009) La prise en charge chirurgicale des améloblastomes mandibulaire. These, Médecine humaine: Marrakech, $116 \mathrm{p}$.

[15] Yang, W., Zhao, S., Liu, F. and Sun, M. (2014) Health-Related Quality of Life after Mandibular Resection for Oral Cancer: Reconstruction with Free Fibula Flap. $\mathrm{Me}$ dicina Oral, Patología Oral y Cirugía Bucal, 19, e414-e418. https://doi.org/10.4317/medoral.19399

[16] Jortay, A.M. (1998) Réhabilitation anatomique et fonctionnelle après les traitements des cancers bucco-pharyngés. Masson, Paris.

[17] Luo, R., Li, P., Li, W., Li, Y. and Qi, J. (2014) Measures of Health-Related Quality of Life in Huge Ameloblastoma Young Patients after Mandible Reconstruction with Free Fibula Flap. Journal of Hard Tissue Biology, 23, 261-266. https://doi.org/10.2485/jhtb.23.261

[18] Okoturo, E., Ogunbanjo, O., Akinleye, A. and Bardi, M. (2011) Quality of Life of Patients with Segmental Mandibular Resection and Immediate Reconstruction with Plates. Journal of Oral and Maxillofacial Surgery, 69, 2253-2259.

https://doi.org/10.1016/j.joms.2010.10.043 
[19] Linsen, S., Schmidt-Beer, U., Fimmers, R., Grüner, M. and Koeck, B. (2009) Craniomandibular Pain, Bite Force, and Oral Health-Related Quality of Life in Patients with Jaw Resection. Journal of Pain and Symptom Management, 37, 94-106. https://doi.org/10.1016/j.jpainsymman.2006.12.019

[20] Grellet, M. and Soussaline, M. (1990) Traité de Technique chirurgicale stomatologique maxillofaciale. Chirurgie des glandes salivaire et des cancers buccaux. Masson, Paris.

[21] Dzioba, A., Aalto, D., Papadopoulos-Nydam, G., Seikaly, H., Rieger, J., Wolfaardt, J., et al. (2017) Functional and Quality of Life Outcomes after Partial Glossectomy: A Multi-Institutional Longitudinal Study of the Head and Neck Research Network. Journal of Otolaryngology_Head \& Neck Surgery, 46, 56. https://www.ncbi.nlm.nih.gov/pmc/articles/PMC5583999 https://doi.org/10.1186/s40463-017-0236-9

[22] Goiato, M.C., de Medeiros, R.A., Vechiato Filho, A.J., da Silva, E.V.F., Sônego, M.V., de Carvalho, K.H.T., et al. (2015) Prosthetic Rehabilitation of a Patient after a Partial Mandibulectomy. Annals of Medicine and Surgery, 4, 200-203. https://doi.org/10.1016/j.amsu.2015.05.004

[23] Smee, R.I., Broadley, K., Bridger, G.P. and Williams, J. (2012) Floor of Mouth Carcinoma: Surgery Still the Dominant Mode of Treatment. Journal of Medical Imaging and Radiation Oncology, 56, 338-346. https://doi.org/10.1111/j.1754-9485.2012.02387.x

[24] JCDR—Marginal Mandibulectomy, Lip plumper, Magnets. https://www.jcdr.net/article fulltext.asp?id=772

[25] Namaki, S., Matsumoto, M., Ohba, H., Tanaka, H., Koshikawa, N. and Shinohara, M. (2004) Masticatory Efficiency before and after Surgery in Oral Cancer Patients: Comparative Study of Glossectomy, Marginal Mandibulectomy and Segmental Mandibulectomy. Journal of Oral Science, 46, 113-117. https://doi.org/10.2334/josnusd.46.113

[26] Aimaijiang, Y., Otomaru, T. and Taniguchi, H. (2016) Relationships between Perceived Chewing Ability, Objective Masticatory Function and Oral Health-Related Quality of Life in Mandibulectomy or Glossectomy Patients with a Dento-Maxillary Prosthesis. Journal of Prosthodontic Research, 60, 92-97.

https://doi.org/10.1016/j.jpor.2015.07.005 